\title{
The Changing Face of Managed Care Pharmacy and the Role of PBMs
}

\begin{abstract}
Managed care has been at the center of the changing health care landscape for many years. Since the early 1980s, pharmacy benefit management (PBM) companies have led the way in innovative outpatient drug formularies, rebate contracting, and clinical pharmacy strategies. Now, however, there is a general consensus in managed care that PBMs must change their core business if they are to survive into the next century.
\end{abstract}

\section{II

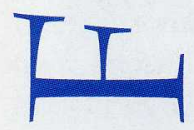

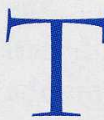

he driving force behind the original PBM strategy was drug for-

mulary design and manufacturer contracting. This enabled health plans to leverage their purchasing power with the pharmaceutical industry. Pharmaceutical companies gained formulary access for their products in exchange for financial compensation in the form of rebates. Health plans then used these rebates to offset increases in pharmaceutical spending and administrative overhead. For several years this system worked well, allowing PBMs to proliferate and gain strength and influence with pharmaceutical manufacturers. However, by 1993 PBMs were so powerful that many manufacturers decided to buy their own PBM or change the contracting strategies that they used with existing PBMs. During this time, the top three PBMs-MEDCO, PCS, and DPS - were bought and manufacturers employed a new type of rebate contract.
LESLIE EPSTEIN, Ph.D, is President and CEO of Think Zebras!, a health care consulting firm in Owings Mills, MD.

Copyright (C) 1997, Academy of Managed Care Pharmacy, Inc. All rights reserved. 
The strategy to trade drug rebates for formulary access evolved into rebates for increased market share. Pharmaceutical manufacturers began demanding that PBMs help increase market share of their products within a particular patient population. This resulted in manufacturers becoming more selective about who they would contract with and what type of financial arrangements they would offer. In essence, the manufacturer would reward only those companies that truly had formulary control and could demonstrate significant gains in share.

\section{PBMS RESPOND TO CHANGE}

For their part, PBMs have responded to these changes with their own strategies. For one, they have tightened drug formularies and listed fewer entities under each therapeutic category. PBMs have encouraged health plans to move from an open formulary, allowing any drug to be a covered benefit, to a closed formulary, in which only certain drugs would be covered. At the same time, contracts have begun to focus on a smaller number of pharmaceutical partners to help keep rebate levels high. With the same goal in mind, PBMs also have discouraged customization of formularies based on the local market Pharmacy and Therapeutics (P\&T) committee input.

The changes in $\mathrm{P} \& \mathrm{~T}$ committee power and structure have resulted in conflicts between providers and health plans, as well as between health plans and PBMs. Traditionally, health plans relied on local P\&T committees to oversee everything from formulary content and structure to preauthorization and drug coverage issues. The shift in power toward the pharmaceutical industry has eroded the feelings of autonomy and power that $P \& T$ committees traditionally enjoyed. In response to the pressure to conform to a one-size-fits-all formulary direction, many health plans and $P \& T$ committees are demanding more autonomy and impartiality in the name of quality health care.

Programs to help plans increase market share also have increased in number and scope. These programs often incorporate patient and provider education, case findings, provider profiling, and academic detailing. Clinical pharmacy programs rely more on sophisticated data manipulation, requiring ad hoc reporting on the latest pharmaceutical issues at the touch of a keyboard. Providers are being held at financial risk for pharmacy costs, and they are asking for detailed information on their prescribing patterns, along with comparative data broken out by medical specialty, practice site, and employer group level. These data requirements, in turn, demand more sophisticated information system technology that can combine pharmacy, medical, and laboratory data.

\section{THE IMPACT OF INDUSTRY CONSOLIDATION}

To complicate the landscape even further, industry consolidation has entered the picture on a grand scale. In recent years, health plans have merged at a rapid pace, creating huge entities covering millions of lives with multiple product lines. Huge multistate insurers, such as Columbia/HCA and AETNA U.S. Healthcare, have changed the face of health care delivery, evaluating both product lines and the delivery system to make each as cost-effective and efficient as possible.

The pharmacy directors of these huge plans are a different animal as well. Here, they are sophisticated purchasers with extensive managed care experience in many practice settings. Today's pharmacy directors are more than capable of providing or creating some, if not all, of the services traditionally offered by PBMs. However, health plans are starting to demand more flexibility in the type and number of services they offer. In essence, they are looking for the ability to choose components to complement their core competencies, and pharmacy directors need to be capable of ensuring that this wide scope of services can be offered.

\section{PHARMACY MANAGEMENT TODAY}

A look at the needs of three hypothetical health plans offers some insight into the changing face of managed care pharmacy management. Health plan A has a dynamic and progressive information systems department with competent data warehousing capabilities. The group is able to combine lab, pharmacy, and medical claims data into a single database and has the technology to query off this data, thereby gaining insight into the overall costs of providing care for each disease state. However, plan A lacks claims processing expertise and wishes to purchase this service from a vendor. In addition, the group wants to hold its own pharmacy contracts within its local service area while enjoying the advantage of a national network for pharmacy needs outside its main geographic service area. Plan A also wants to explore the advantages of mailservice for its growing Medicare population and expand these services through the claims processing vendor. However, plan A's pharmacy director has a clinical staff of pharmacists and does not need much clinical pharmacy support. The challenges faced by a PBM bidding on this plan would be to structure services to meet the pharmacy director's needs.

Plan B has different needs. Here, the pharmacy director has state-of-theart claims processing services and a wide national pharmacy network. However, plan B lacks a way to combine' medical, pharmacy, and laboratory claims data. The plan's information systems cannot support ad hoc reporting or data warehousing. The group also needs extensive clinical pharmacy support, including a P\&T committee. At the same time, plan B's mail-service vendor is different from its clinical pharmacy vendor, and the group wants to combine these services. The PBM serving this plan may be called on to provide services that include P\&T monograph development, secretarial support, and management services. Plan B also may require support in preauthorization programs, counter-detailing, and exten- 
sive pull-through support. The challenge facing the bidding PBM here is integrating the health plan's claims processing system and national network into its overall package.

Finally, plan $C$ wishes to insource drug formulary contracting. The new pharmacy director here previously worked in contracting for a PBM and is familiar with the process. However, the plan's information systems department cannot support claims processing, ad hoc reporting, or data integration/warehousing. The plan wishes to hold its local contracts and only contract with several pharmacy chains for out-of-area services. The pharmacy director wants to schedule, coordinate, and direct the P\&T committee, but he wants the PBM to deliver clinical monographs and support as needed. Ad hoc reporting needs to be available on the director's personal computer, with technical support and back up available on an as-needed basis. Mail service needs to be integrated into local and national network strategies, with little or no effect on patient care. The challenge to the bidding PBM in this case is to provide services without formulary control, rebates, or coordination.

\section{THE MANY FACES OF PBMS TODAY}

The hypothetical situations discussed here illustrate the need for PBMs to be flexible and wear a variety of hats. To meet the challenges of a changing market, some may retreat back into their core competencies. For example, a company that grew out of claims processing may focus on increasing its value in that particular area. This company may invest more in information systems development, creating new and innovative approaches to gathering pharmacy information at the point-of-sale.

PBMs that were outgrowths of mail-service will continue to focus on increasing and enhancing services in this area. Innovations in robotics and packaging will provide increasing opportunities for high-volume, low-cost, and high-quality pharmacy services. Integrated clinical pharmacy and disease management programs will provide added value to clients. Pharmacists can focus on issues such as compliance, patient counseling and education, and elevating the quality of care for patients on long-term drug therapy. Offering specialty services surrounding specific disease states can help coordinate pharmacy care, decrease costs, and in-crease the positive effects of pharmaceutical care.

PBMs that grew out of infusion therapy and clinical pharmacy services may choose to focus on expanding these services. For example, infusion therapy vendors may expand their offerings into specialized disease management programs. Clinically-driven PBMs may refine and expand drug utilization, preauthorization, and disease management programs. Ad hoc reporting may grow even more sophisticated and incorporate other medical data elements in clinical evaluations.

Still other PBMs will decide to move away from the services and business strategies that launched their success. Some may choose to become specialized disease-management vendors, either focusing on an array of diseasemanagement programs or several niche programs. Others may become information systems experts, focusing on data warehousing, data integration, collection, and reporting. Case management, demand management, and provider profiling are still other areas that offer opportunities for growth. However, it is important to note that all of these initiatives will require significant capital to develop. Therefore, some PBMs either will become part of larger corporations or form publicly held entities.

Another avenue for PBMs to travel is the road to accreditation. The require- ment for National Commission for Quality Assurance (NCQA) accreditation is becoming the driving force behind many health plans' quality assurance and total quality management programs.

\section{ADAPTING TO SHIFTS IN POWER}

All PBMs share the need to adapt to their client bases' shifts in power. They need to complement their skills and increase their staffing levels. Quick response time and the flexibility to address specific client needs are essential elements for continued success. PBMs need to acknowledge the new breed of managed care pharmacy directors and the level of skills and expertise that many health plans now possess internally.

Increasingly, PBMs will be pressed to develop programs and systems to address undefined needs and expectations. Clients want to choose from care component modules, extracting those elements most complementary to their core competencies. Existing hardware and software must be state-of-the-art and keep pace with the increasing demand for more data and better reporting.

Above all, PBMs must listen to their clients, deviate from their 'one-sizefits-all' approaches, and develop carecomponent modules from which clients can choose services.

The future of PBMs depends on their ability to change and focus on their core competencies. They must explore new technologies and strategies and lead the marketplace in developing solutions to information management and reporting. They also must respect the managed care organization's expertise and offer clients complementary solutions to achieve their goals. PBMs constantly must be on the lookout for new avenues of services and areas in which they can expand. 